\title{
Experimental Investigation of drying process for Mixed Municipal Solid Waste: Case Study of Wastes Generated in Nairobi, Kenya
}

\author{
Antony M. Nzioka ${ }^{1}$, Hyeon U. Hwang ${ }^{1}$, Myun G. Kim ${ }^{1}$, Alexey G. Troshin ${ }^{2}$, \\ Yan CaoZheng ${ }^{1}$, and Young J. Kim ${ }^{1 *}$
}

\begin{abstract}
The viability of improving recyclability of unsorted Municipal Solid waste in devolved Governments and/or counties such as in Kenya through drying is discussed in this paper. In particular, the possibility of drying unsorted Municipal Solid waste based on patented process was proposed and discussed in depth because of the resource-rich nature of the waste generated .The proposed patented process was designed to reduce further accumulation of unsorted Municipal Solid Wastes as well as enhance recycling recyclable materials present in the unsorted wastes. The objective of this research was to investigate the effects of various factors on the drying rate of unsorted municipal solid waste. The loose and particulate nature of the unsorted Municipal solid waste was considered in this investigation. The composition of the samples investigated composed reflected typical composition of waste collected in Nairobi. Weight losses of the samples were measured on real-time basis in the experimental investigation with the aim of determining drying rate with respect to unsorted Municipal Solid wastes. Effect of the size of samples on the rate of drying was investigated. In addition, effect of different composition of different components in the sample on the drying rate was investigated. The effect of different temperature on the rate of drying was also investigated. Results from experiment showed that drying rate increased with an increase in temperature. In addition, the nature and composition of the waste also affected the drying rate of unsorted Municipal Solid waste. Finally, based on obtained results, it is evident that recycling of wastes through proposed drying process will significantly improve the recyclability of wastes.
\end{abstract}

Keywords-Unsorted Municipal Solid wastes, Drying, Drying rate, Temperature, loose and particulate materials.

\section{INTRODUCTION}

$\mathrm{U}$ JNSORTED Municipal Solid Wastes (MSW) is a key issue affecting growth and development of such rapidly developing countries such as Kenya. Existing solutions implemented for handling and treating wastes such as landfilling among others have not only raised concerns related to environmental pollution, but have also been, to an extent, a source of socio-economic problems [2]. Such similar socioeconomic problems have also been witnessed in other developing countries such as Lebanon [1] and could be

\footnotetext{
${ }^{1}$ Kyungpook National University, Daegu, South Korea

${ }^{2}$ National Technical University "Kharkov Polytechnic Institute", Kharkov, Ukraine.
}

destabilizing factor for any country. Sustainable Municipal Solid waste treatment solutions have been developed and implemented in developed Countries such as South Korea and EU states with an aim of solving the MSW problem. For example in the Republic of Korea, integrated waste management system was designed and developed in order to increase recyclability and safe disposability of waste from the point of generation to disposal point [3]. As a result, Republic of Korea has not only achieved significantly higher recycling rates of MSW, but also implemented effective waste-to-energy technologies [4]. The same tendency may also be witnessed in EU where RDF technology has been implemented as an effective method of recycling highly calorific wastes [5]. These noble solutions will require sorting of waste from the collection point as well as necessary policy implementation supporting it. However as noted by UNEP and Cal Recovery [2], such sustainable practices (e.g. sorting) may be difficult to implement due to socio-economic factors as well as inadequate policy guidelines related to the same. It is due to these reasons that existing MSW management and disposal practices such as landfilling are used till this day. These in turn will lead to reduction of land resources among other resources as well as creating legal responsibilities and liabilities related to unsorted MSW handling [6, 7].

In view of the existing problem and the need to dispose unsorted MSW, Troshin et al. [8] proposed a method in which the unsorted MSW from collection point may be processed through thermal processes. This proposed method, as shown in fig. 1, aims at separating the recyclable waste (e.g. glass, metals,) and treating the remaining wastes through thermal means so as to generate products with high calorific value and less toxic. This proposal is based on the fact that the biggest proportion of the wastes generated consists of materials with considerable calorific value. Drying of unsorted MSW is one of the steps proposed by Troshin et al. Statistical information provided by $[9,10]$ indicate the presence of substantial amount of water content in the MSW generated in developing countries. Therefore drying process, which is part of the proposed method, will be necessary.

The objective of this research is to investigate the effects of various factors on the drying rate of unsorted municipal solid waste as well as highlight the significance of drying unsorted 
MSW as part of sustainable solution in developing countries. Several studies related to drying processes have been conducted by different authors. Majority of authors have focussed on bio-drying as a viable solution for unsorted MSW. In Particular, Zhang et al. [11] focussed on feasibility of increasing sorting efficiency and combustibility of MSW after bio-drying. Ragazzi et al. [12] investigated on MSW characteristics after bio-drying. However, the aforementioned studies among other studies have shed little information on drying process of unsorted MSW using effective methods similar to the one proposed by Troshin et al. In particular, little or no studies were conducted on the effect of various factors on the drying rate for typical wastes generated in developing countries.

The motivation behind this study was to investigate the effect of composition, and temperature on the overall drying rate of the unsorted MSW. These objectives were achieved by conducting experiment at different temperatures and while at the same time altering the composition of the waste

\section{MATERIALS AND METHODS}

Sample materials composed of food waste, paper, plastics and soil. The aforesaid materials were used as representation of typical composition of waste generated in developing countries such as Kenya. In conducting this study, the following limitations were noted: there was limited statistical data regarding proximate composition of MSW; MSW generated is usually heterogeneous, with varying composition of all components and flaky thereby reducing uniformity of overall composition in the MSW. Putting into consideration the aforementioned limitations, available data suggested by Njoroge and Henry et al $[9,10]$ were used as the basis for calculation. Due to the flaky nature the MSW, the sample used were reduced in sized with the aim of ensuring uniformity in composition after mixing. Based on the recommendation proposed by Athanasopoulos G. A.[13], the particle sizes of the mixed waste analyzed was $<20 \mathrm{~mm}$ particle size. Particle sizes were determined using formula proposed by Keey R.B [14] whereby the equivalent diameter of a flaky material (MSW) could be determined by the volume it displaces. Therefore, the equivalent diameter $\left(d_{e}\right)$ of the mixed waste was determined using the following equation [14]:

$$
d_{e}=\left(\frac{6}{\pi} V\right)^{\frac{1}{3}}
$$

where, $V$ represents the volume displaced by mixed wastes, which may be determined using the following equation:

$$
V=\alpha d_{p}^{3}
$$

Variable $d_{p}$ was determined using the expression suggested by Keey and could be expressed as follows:

$$
d_{p}=\left(\frac{4}{\pi} B L\right)^{0.5}
$$

where, variables $B$ and $L$ represented length and breath of the wastes analyzed.
Food waste was obtained from the University's dining hall, paper composition consisted of shredded paper and the plastic composition composed of plastic stuffing used in packaging. Soil used was obtained from University's territory while the wood chips represented the wood composition in the experiment. The drying equipment used for this experimental investigation was convective drying oven (Han Baek HB502L). In order to achieve all the objectives of this experimental study, a set of 5 samples each weighing 100 gr. of mixed MSW, were used. 4 samples were used to analyse mass losses and/ or drying rate while the $5^{\text {th }}$ one was used to analyse overall moisture content.

During experiment, each sample was put in a wire mesh such that the thickness of the sample layer analyzed did not exceed $30 \mathrm{~mm}$. The wire mesh plus the sample were placed in the middle of the oven and mass losses were recorded on realtime basis using digital balance (Sartorius TE 612-L). In addition, overall moisture content for sample used was obtained by drying the separate sample in the drying oven (DR - 1102) at a temperature of $105^{\circ} \mathrm{C}$ for 2 hours. The residual moisture content $(\%)$ was calculated by means using the following expressions [15]:

$$
X=\frac{W_{i s}-W_{d s}}{W_{d s}} \times 100
$$

where $X$ is moisture content, $W_{i s}$ is initial sample mass, $W_{d s}$ is the mass of dried waste. Drying rate (gr.water/gr. dry waste/time) was calculated using the expression proposed by A. Tahmasebi et al. [17].

$$
\frac{W_{w s 1}-W_{w s 2}}{W_{d s}\left(t_{2}-t_{1}\right)}
$$

\section{RESULTS AND DISCUSSION}

\section{A. Effect of different temperature on drying rate}

In order to investigate the effect of temperature on drying rate 3 different temperatures were randomly selected between $50^{\circ} \mathrm{C}$ and $100^{\circ} \mathrm{C}$, i.e. $60^{\circ} \mathrm{C}, 80^{\circ} \mathrm{C}$ and $100^{\circ} \mathrm{C}$. A set of 4 samples with similar weight (100 gr.) were used to investigate drying rate for each temperature for $30 \mathrm{~min}$. The particle size for sample used, determined using expression above, was <20 mm. Sample waste analyzed composed of $60 \%$ food waste, $15 \%$ Plastic shreds, $15 \%$ paper shreds, $5 \%$ wood chips and $5 \%$ soil by weight. Graphic representation of weight loss vs. time and changes in water content vs. time were obtained and shown in fig 2. Results obtained from the experimental study showed that an increase in temperature resulted to an increase in drying rate by a factor of 1 . Experimental drying rate for sample $1-1$ dried at $60^{\circ} \mathrm{C}$ for 30 minutes was $7 \times 10^{-3} \mathrm{~g}$. water/g. dry waste/min. Experimental drying rate for sample 2 -1 dried at $80^{\circ} \mathrm{C}$ for 30 minutes was $8 \times 10^{-3} \mathrm{~g}$. water $/ \mathrm{g}$. dry waste/min while that of sample $3-1$ was $7 \times 10^{-3} \mathrm{~g}$ water/g. dry waste/min. This was an indication of the important role temperature plays in intensification of drying process. 


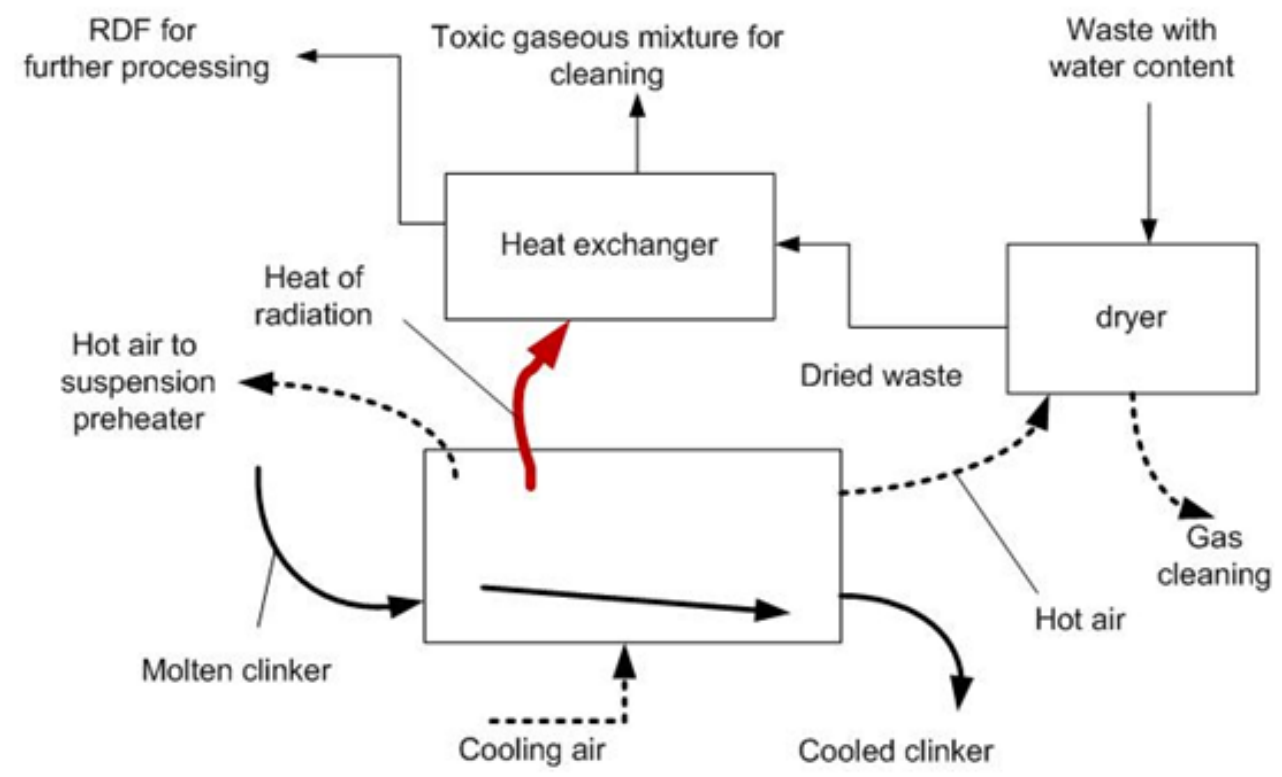

Fig. 1: Schematic Diagram of Integrated Refuse Derived Fuel Production Process and Cement Clinker Cooling Process proposed by Troshin et al

\section{B. Effect of Changes in Composition on the Drying Rate}

\section{a. Case I}

In this part, 3 different sets of sample wastes of with different composition were analyzed at $60^{\circ} \mathrm{C}$. One set of sample $(1-2)$ consisted of composed $60 \%$ food waste, $15 \%$ Plastic shreds, $15 \%$ paper shreds, $5 \%$ wood chips and $5 \%$ soil by weight. Second set of sample $(2-2)$ consisted of $50 \%$ food waste, $20 \%$ paper shreds, $15 \%$ plastic shreds, $10 \%$ soil and $5 \%$ wood chips by weight. Third set of sample $(3-2)$ analyzed consisted of $70 \%$ food waste, $15 \%$ paper shreds, $10 \%$ plastic shreds, 5\% wood chips and 5\% by weight soil. Experimental results are shown in fig. 3. From the results, obtained, sample $1-2$ had a drying rate of $7 \times 10^{-3} \mathrm{~g}$. water $/ \mathrm{g}$. waste/min which was higher than the rest. Sample $2-2$ and $3-2$ had drying rates of $5 \times 10^{-3} \mathrm{~g}$. water $/ \mathrm{g}$. waste $/ \mathrm{min}$ and $4 \times 10^{-3} \mathrm{~g}$. water $/ \mathrm{g}$. waste/min respectively. Although the results did not show any correlation between changes in composition and drying rate at lower temperatures, it was evident hat higher water content in the sample was the significant driving force for drying process than low water content. These results coincide with investigation results done by Keey R [14].

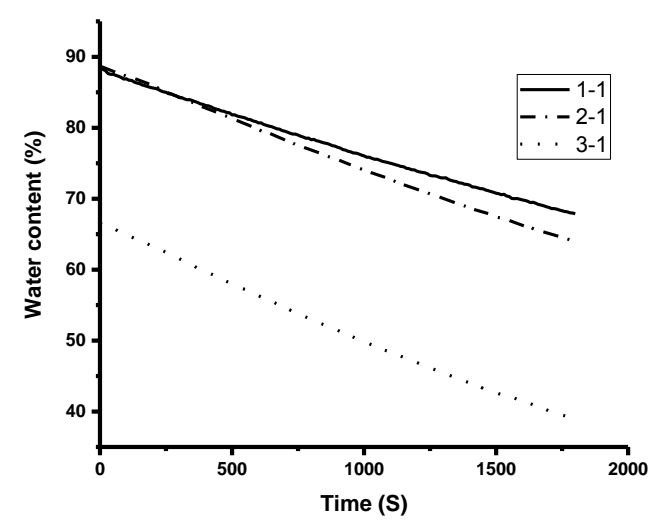

Fig. 2. Drying curves for mixed wastes at $60 \circ \mathrm{C}, 80^{\circ} \mathrm{C}$ and $100 \circ \mathrm{C}$

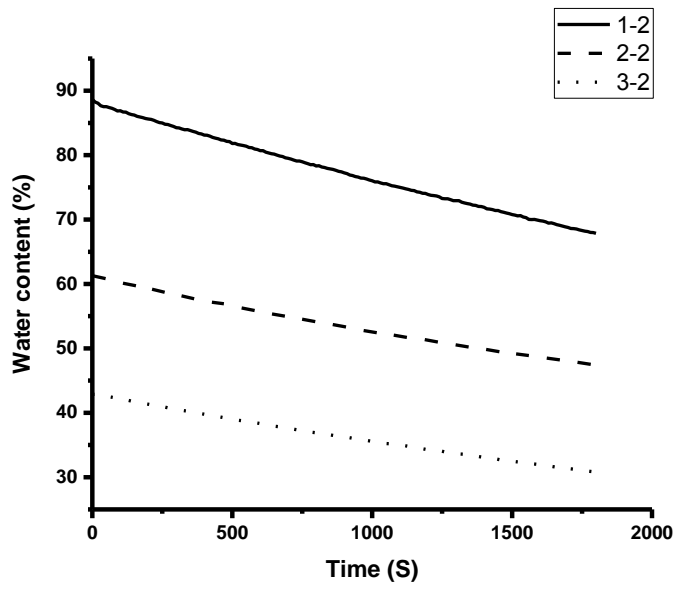

Fig. 3. Drying curves for mixed wastes with different composition undertaken at a temperature of $60^{\circ} \mathrm{C}$ 


\section{b. Case II}

In this part, 3 different sets of sample wastes of with different composition were analyzed at $80^{\circ} \mathrm{C}$. One set of sample $(1-3)$ consisted of composed $60 \%$ food waste, $15 \%$ Plastic shreds, $15 \%$ paper shreds, $5 \%$ wood chips and $5 \%$ soil by weight. Second set of sample $(2-3)$ consisted of $50 \%$ food waste, $20 \%$ paper shreds, $15 \%$ plastic shreds, $10 \%$ soil and $5 \%$ wood chips by weight. Third set of sample $(3-3)$ analyzed consisted of $70 \%$ food waste, $15 \%$ paper shreds, $10 \%$ plastic shreds, $5 \%$ wood chips and $5 \%$ by weight soil. From the results obtained (fig. 4), sample all the samples analyzed exhibited similar drying $\left(7 \times 10^{-3} \mathrm{~g}\right.$. water $/ g$. waste/min $)$ irrespective of the water content present and the changes in the composition of the sample. This showed that changes in composition did not affect the drying rate. However, drying rate increased as a result of an increase in temperature.

\section{c. Case III}

In this part, 3 different sets of sample wastes of with different composition were analyzed at $100^{\circ} \mathrm{C}$. The results were shown in fig. 5. One set of sample $(1-4)$ consisted of composed $60 \%$ food waste, $15 \%$ Plastic shreds, $15 \%$ paper shreds, $5 \%$ wood chips and $5 \%$ soil by weight. Second set of sample $(2-4)$ consisted of $50 \%$ food waste, $20 \%$ paper shreds, $15 \%$ plastic shreds, $10 \%$ soil and 5\% wood chips by weight. Third set of sample $(3-4)$ analyzed consisted of $70 \%$ food waste, $15 \%$ paper shreds, $10 \%$ plastic shreds, $5 \%$ wood chips and $5 \%$ by weight soil. From experimental results obtained (fig. 5), no correlation was seen between changes in composition and drying rate. However, experimental data showed that at higher temperatures and higher water content, the driving force for drying process and drying rates were increased.

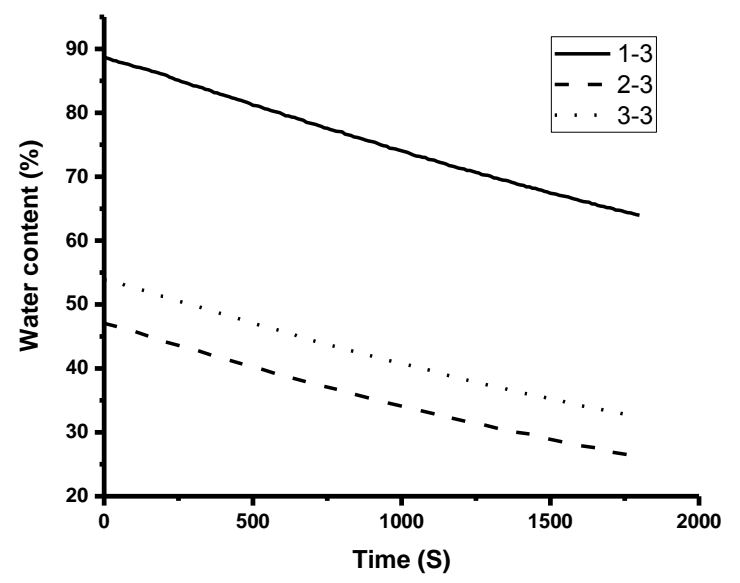

Fig. 4. Drying curves for mixed wastes with different composition undertaken at a temperature of $80^{\circ} \mathrm{C}$

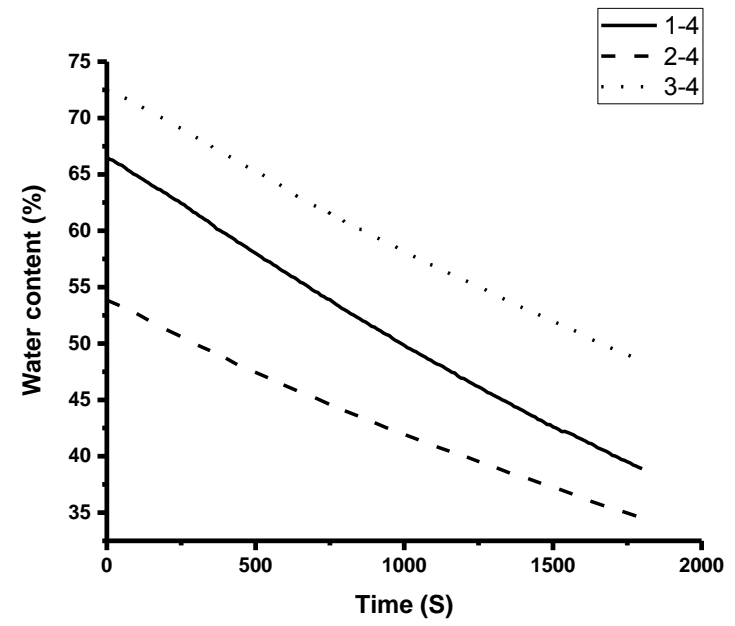

Fig. 5. Drying curves for mixed wastes with different composition undertaken at a temperature of $100^{\circ} \mathrm{C}$

\section{CONCLUSION}

Experimental investigation analyzing the influence of temperature and composition was conducted and from the results obtained, the following conclusions could be made:

- Temperature could be considered as one of the factors affecting the rate of drying. Rate of drying increased with an increase in temperature.

- Effects of changes in composition of food waste on the drying rate were not exhibited in the experiment. However, water content present and temperature were the main driving force in the drying process. Therefore intensification of the drying process could be effective enough to achieve considerably higher drying efficiency.

\section{ACKNOWLEDGMENT}

I would like to acknowledge the support granted by BK21 plus and NIIED, Republic of Korea.

\section{REFERENCES}

[1] Alarabiya News. Rain produces rivers of trash in Lebanese capital. Online newspaper article posted on $25^{\text {th }}$ Oct. 2015, available: http://english.alarabiya.net/en/News/middle-east/2015/10/25/Rainproduces-rivers-of-trash-in-Lebanese-capital-.html.

[2] UNEP, Cal Recovery Inc. Solid Waste Management, Osaka, Japan: UNEP, 2005. pp. 558.

[3] Ministry of Environment, Republic of Korea. "Waste Management and Reduction," Online website available: http://eng.me.go.kr/eng/web/index.do?menuId $=367 \&$ findDepth $=1$.

[4] Waste Management World, "Republic of Korea honoured by Waste-toEnergy Research and Technology Council" online website resource available: http://waste-management-world.com/a/republic-of-koreahonoured-by-waste-to-energy-research-and-technology-council-2014award

[5] A. Gendebien, A. Leavens, K. Blackmore, A. Godley and others, Refuse Derived Fuel: Current practices and perspectives. Swindon,U. K.: WRc, 2003, pp. 219.

[6] Handbook of solid waste management and waste minimization technologies A. Cheremisinoff, Oxford, U.K.: Elsevier Science, p. 492.

[7] A. Bagchi, A. Bhattacharya. (February 2015). Post-closure care of engineered municipal solid waste landfill. Waste. Manage. Res. [Online]. 33(3). $\quad$ pp. $232 \quad-\quad 240 . \quad$ available: http://wmr.sagepub.com/content/33/3/232 
http://dx.doi.org/10.1177/0734242x14567501

[8] A. G. Troshin, A. M. Nzioka, "Method of processing unsorted municipal solid waste utilising heat energy from reciprocating grate cooler during cooling process (Ukrainian),” Ukraine Patent № 83321 Cl. MPK (2013.01) F26B 3/00, 10, September. 2013.

[9] B. A. Njoroge, M. Kimani, D. Ndunge, (February 2014). Review of municipal solid waste management: Case study of Nairobi, Kenya. International Journal of Engineering and Science. [Online]. 4(2). pp. $162-20 . \quad$ Available: http://www.researchinventy.com/papers/v4i2/C04216020.pdf

[10] A. K. Henry, Z. Yongsheng, D. Jun. (2005). Municipal solid waste management challenges in developing countries - Kenyan case study. Waste Manage. [Online]. 26. pp. 92 - 100. Available: http://www.sciencedirect.com/science/article/pii/S0956053X05001121

[11] D. Zhang, P. He, L. Shao. (July 2009). Sorting efficiency and combustion properties of municipal solid waste during biodrying. Waste Manage. [Online]. 29. pp. 2816 - 2823. Available: http://www.sciencedirect.com/science/article/pii/S0956053X09002414

[12] E. C. Rada, M. Ragazzi, V. Panaitescu, T. Apostol, "Experimental characterization of municipal solid waste bio-drying," $3^{\text {rd }}$ International Conf. on Waste Management and the Environment, 2006, pp. 295 302. http://dx.doi.org/10.2495/wm06032

[13] G. A. Athanasopoulos, "Laboratory testing of municipal solid waste," Proc. 2008 International Symposium on Waste Mechanics, 2008, pp. $195-205$.

[14] R. B. Keey, Drying of loose and particulate materials, New York, U.S.A.: Hemisphere, 1991, ch. 2, pp. $11-27$.

[15] B. S. Sazhin, Principles of Drying Technique (Russian), Moscow: Khimiya, 1984, pp. 320.

[16] C. Strumillo, T. Kudra, Drying: Principles, applications and design, Montreux, Switzerland: Gordon and Breach Science, 1986, pp. 448.

[17] A. Tahmasebi, J. Yu, X. Li, C. Meesri. (October 2011). Experimental Study on microwave drying of Chinese and Indonesian low-rank coals. Fuel Process. Technol. [online]. 92. pp. 1821 - 1829. available: http://www.sciencedirect.com/science/article/pii/S0378382011001251. http://dx.doi.org/10.1016/j.fuproc.2011.04.004 